\title{
Л.Л. ГОНЧАРОВА (ДУІТ)
}

Кафедра «Автоматизація та комп'ютерно - інтегровані технології транспорту», Державний університет інфраструктури і технологій, 03049, Київ - 49, вул. Лукашевича, 19, тел.: 099-288-12-08, ел.пошта: ktarael@yandex.ru

\section{ДИФЕРЕНЦІЙНІ МОДЕЛІ ІНТЕЛЕКТУАЛІЗАЦІЇ ПРОЦЕСІВ МОНІТОРИНГУ ЕЛЕКТРИЧНОГО ОБЛАДНАННЯ ТЯГОВИХ ПІДСТАНЦІЙ}

\section{Вступ}

Тенденції перспективних наукових досліджень в сфері енергетики і залізничних систем електропостачання глибоко пов'язані з бурхливим розвитком інтегральних технологій створенням надвеликих інтегральних схем та мікропроцесорних комплектів i, на їх основі, новітніх інформаційних, мережевих та комунікаційних технологій керування швидкоплинними режимами електропостачання [1]. Пошук нових напрямків досліджень процесів оптимізації режимів електропостачання показав, що подальший розвиток інноваційного перетворення тягових мереж залізниць базується на концепції розумної енергетики і може бути реалізований шляхом інтелектуалізації комплексу швидкоплинних технологічних процесів в сфері генерації електроенергії, споживання, передачі та розподілу, включаючи сервісне обслуговування в умовах ринку $[5,6]$. Загальновизнані у світі дослідження, в сфері інтелектуалізації енергетичні процеси, отримали назву SMART Grid - технології, завдяки яким, на основі єдиного розподіленого інтегрованого обчислювального середовища, інноваційне перетворення залізничних мереж може бути реалізовано шляхом організації глибокої взаємної інтеграції електромережевої топології та архітектури розподіленої комп'ютерної мережі, що відкриває можливість наповнювати залізничну енергетику новими «знаннями» $[1,2]$. Електричні мережі залізниць характеризується великою кількістю силового електричного обладнання функціонуючого в широкому діапазоні частот, значною величиною «рухомого» навантаження та динамікою режимів споживання електроенергії, а також великим рівнем перешкод, в зв'язку з несиметричністю навантаження обумовленою організацією однофазної тягової мережі живлення змінного струму. Рішення комплексу задач, інноваційного перетворення тягових електричних мереж залізниць, можливо шляхом створення сучасних інтелектуальних технологій оптимізації електропостачання, різкого підви- щення ефективності функціонування режимів тягових електричних мереж та накопичування нових знань включаючи формування сучасних комерційних відносин в сфері ринку електроенергії. Проведенні дослідження показали, що головним, при формуванні інтелектуальних технологій електропостачання, $\epsilon$ організація безперервного комп'ютерного моніторингу комплексу параметрів режимів енергосистеми і визначення на їх базі всієї інформативності первинної інформації як основи повномасштабного інформаційного забезпеченням процедур оптимізації електроспоживання, аналізу технічного стану та прогнозу аварій, розширення комерційних можливостей, формування комп'ютерної культури електроспоживання i стимулювання економічного розвитку.

\section{Постановка проблеми}

Останні досягнення в області інформаційних та інтелектуальних технологій оперативного і стратегічного управління електропостачанням на тягу відкрили ряд можливостей в сфері формування, в реальному часі, керуючих впливів оптимізації режимів електропостачання, також проводится безперервне кількісне i якісне спостереження швидкозмінних параметрів, притаманних специфічним особливостям електромереж залізничного транспорту. Концептуальною основою створення інноваційних систем електропостачання, представляється організації сумісного та і узгодженого рішенні комплексу глобальних задач підвищеної інформаційної складності і розмірності проведення всережимного інтелектуального комп'ютерного моніторингу параметрів режимів систем електропостачання для комплексної оцінки прогнозу технічного стану системи вцілому, формування комерційних складових управління ресурсами і вимогам сучасних бізнес - процесів, сервізних ринкових послуг та забезпечення високого рівня експлуатаційних характеристик. Враховуючи велику швидкість протікання технологічних

процесів, пов'язаних 3 електропостачанням, i найрізноманітніші зв'язки між подіями, що 
3'являються в електричних системах, принциповою відмінністю інтелектуального комп'ютерного моніторингу в залізничній енергетиці $є$ те, що комплекс процедур реєстрації первинної інформації в процесі моніторингу, представляється не тільки як спостереження поточного стану електричного об'єкту, а й включає ретроспективний аналіз та прогноз режимів функціонування в різноманітних умовах зовнішнього середовища, формування нових знань, пов'язаних з інтеграцією інтелектуальних комп'ютерно - орієнтованих методів моделювання, а також представлення інформації, яка відображається у вигляді даних, показань, суджень, графіків, тощо. Головною відмінністю поняття інтелектуального комп'ютерного моніторингу в залізничній енергетиці від класичного заключаються, в першу чергу, в великій своєрідності і різноманітності фізичних явищ і задач розв'язання яких необхідно проводити в реальному часі, що потребує комп'ютерного забезпечення безперервності процесу електроспоживання, пов'язаного з безпекою перевезень. Організація інтелектуального комп'ютерного моніторингу потребує розробки нових підходів і створення інтелектуальних методів синтезу інноваційних мереж електропостачання, а отримані нові знання, на базі яких, відкривають можливість зробити суттєвий ривок в сфері перспективних енергозберігаючі технологій на залізничному транспорті, поставити ряд проблем конструювання інтелектуального силового електричного обладнання та методик їх експлуатації.

Метою роботи є створення, на основі теорії диференційних перетворень, математичних моделей і комп'ютерно - орієнтованих методів інтелектуалізації процесів безперервного моніторингу i оцінки технічного стану мереж електропостачання і силового обладнання тягових підстанцій.

\section{Диференційні моделі}

Процедури інтелектуалізації оперативних і стратегічних рішень базуються на проведенні, в реальному часі, інтелектуального комп'ютерного моніторингу сукупності внутрішніх і зовнішніх параметрів енергомережі, представлених виразом виду [1-4]

$$
i_{k}=F_{k}^{i}\left(i_{k}^{d}, i_{k}^{a}, i_{k}^{p}, U_{k}, t_{k}, D_{j}, \theta_{\theta}, f, \tau, U_{k}^{i}, Z_{k}^{i}, V_{k}^{i}\right),
$$

(C) Гончарова Л. Л., 2017

$$
\begin{gathered}
u_{k}=F_{k}^{u}\left(u_{k}^{d}, u_{k}^{a}, i_{k}^{p}, i_{k}, t_{k}, D_{j}, \theta_{\theta}, f, \tau, U_{k}^{u}, Z_{k}^{u}, V_{k}^{u}\right), \\
\lambda_{k}=F_{k}^{\lambda}\left(\lambda_{k}^{d}, \lambda_{k}^{a}, \lambda_{k}^{p}, i_{k}, u_{k}, t_{k}, \theta_{\theta}, f, \tau, U_{k}^{\lambda}, Z_{k}^{\lambda}, V_{k}^{\lambda}\right), \\
D_{j}=F_{j}^{D}\left(D_{j}^{d}, D_{j}^{a}, D_{j}^{p}, i_{k}, u_{k}, t_{j}, \theta_{\theta,}, \tau, U_{j}^{D}, V_{j}^{d}\right), \\
k=1,2 \ldots . n, j=1,2 \ldots n
\end{gathered}
$$

де $\lambda_{k}, D_{j}$ - аналогові i дискретні сигнали; $i_{k}^{d}, u_{k}^{d}, \lambda_{k}^{d}, D_{j}^{d}$ - сигнали доаварійного режиму; $i_{k}^{a}, u_{k}^{a}, \lambda_{k}^{a}, D_{j}^{a}$ - сигнали аварійного режиму; $i_{k}^{p}, u_{k}^{p}, \lambda_{k}^{p}, D_{j}^{p}-$ сигнали післяаварійного режиму; $f$ - частота; $t$ - проміжок часу доаварійного режиму; $U_{k}-$ параметри, що визначають синхронність вимірів; $V_{k}$ - параметри, що характеризують ряд особливостей формування первинної інформації; $\Theta$ - параметри даних навколишнього середовища.

Вираз (1) являється основою визначення всієї інформативності зареєстрованих первинних даних для обчислення, 3 підвищеною точністю, кількісних і якісних показників перехідних режимів які протікають в енергомережі, що відкриває можливість суттєвого зниження ризику неадекватного вибору цілей і стратегій при організації інноваційних перетворень залізничної енергетики. Визначення всієї інформативності отриманих первинних даних, в процесі розробки інтелектуальних технологій керування та оптимізації електропостачання, можливо тільки шляхом розробки нових математичних моделей і методів підвищеної інтелектуальної складності і розмірності. С цією метою скористаємось основними положеннями теорії диференційних перетворень Пухова, фундаментальні положення якої представлені наступною парою математичних залежностей [7]

$$
\begin{aligned}
& I(k)=\frac{H^{k}}{k !}\left[\frac{d^{k} i(t)}{d t^{k}}\right] t_{0} \mp \\
& \overline{-}_{i}(t)=\sum_{k=0}^{k=\infty}\left(\frac{t}{H}\right)^{k} I(k)
\end{aligned}
$$

де $i(t)$ - первинна функція аргументу $\mathrm{t}$ яка може бути $\mathrm{f}$ раз диференційована і яка має ряд обмежень включаючи свої похідні; $I(k)$ - диференційне Т - зображення первинної функції $i(t) ; H$ - масштабний коефіцієнт розмірність якого співпадає 3 розмірністю аргументу $\mathrm{t}$, $\mathrm{i}$ вибирається, як правило, із умов $0 \leq t \leq H$ на всьому діапазоні функції - оригіналу $i(t)$; $\mp$ - 
символ відповідності між функцією - оригіналом $i(t)$ і його диференційним Т-зображенням $I_{j}(k)$. Завдяки прямому диференційному перетворенню $I(k)=\frac{H^{k}}{k !}\left[\frac{d^{k} i(t)}{d t^{k}}\right] t_{0}, \quad$ формується диференційне Т-зображення функції - оригіналу $i(t)$ у вигляді дискретної функції $I(k)$ цілочислового аргументу $k=0,1,2, .$. .На основі набору Т-дискрет функції $I(k)$ цілочислового аргументу $I(k), k=0,1,2, .$. використавши зворотне диференційне перетворення $i(t)=\sum_{k=0}^{k=\infty}\left(\frac{t}{H}\right)^{k} I(k)$ отримаємо функцію оригінал $i(t)$. Необхідно відмітити, що при $k=0$, відповідно (1) для будь якого $t_{j} \quad(j=0,1,2, . . m)$ ) виконуються наступні рівності:

$$
\begin{gathered}
I_{0}(0)=i\left(t_{0}\right), I_{1}(0)=i\left(t_{1}\right), \\
I_{2}(0)=i\left(t_{2}\right), \ldots, \\
I_{2}(0)=i\left(t_{2}\right), \ldots, I_{m}(0)=i\left(t_{m}\right)
\end{gathered}
$$

Диференційна модель синхронного вимірі первинної інформації. В процесі моніторингу параметрів режимів електричних мереж і силового обладнання тягових підстанцій, при реєстрації первинної інформації, домінуючою є необхідність виконання, 3 єдиних інформаційних позицій, синхронного вимірювання аналогових i дискретних сигналів в різних вузлах $\mathrm{i}$ сегментах енергосистеми. Результати синхронної реєстрації первинних даних є головними для оцінки та збільшення рівня динамічної стійкості електричної енергосистеми, покращення якості іiі функціонування при передачі енергії споживачам, а також формування, в реальному часі, управлінських рішень $[3,5]$. Забезпечення синхронної реєстрації сигналів, в різних вузлах розподіленої енергосистеми, відкриває також можливість проводити інтелектуальний моніторинг штатних i аномальнихх режимів функціонування електричних мереж, визначати всю глибину інфоримативності отриманої первинної інформації, показати глибину i рівень діагностування силового обладнання в процесі роботи, ідентифікувати аномальні режими роботи, а також реалізувати синхронізацію роботи різних сегментів енергосистеми та проводити контроль перетікання потужностей. Синхронна реєстрація сигналів, в заданих сегментах єдиної енергосистеми, включає процедуру визначення кута $\delta$ кожної фази напруги, або струму в різних точках виміру топології електричної мережі. Вимірювання кутів $\delta$ кожної із фаз напруг i струмів енергосистеми може бути реалізоівано, 3 високою точністью, в єдиному форматі астрономічного часу шляхом привязки до часових сигналів які отримуються від GPS приймача. Синхронний вимір, як показано на рис.1, peалізується шляхом прив'язки до шкали часу GPS при переході через нуль з мінусу на плюс вимірюваних синусоїд напруги або струму. Для визначення $\tau_{\delta}$ i відповідно кута $\delta$, згідно рис. 1.

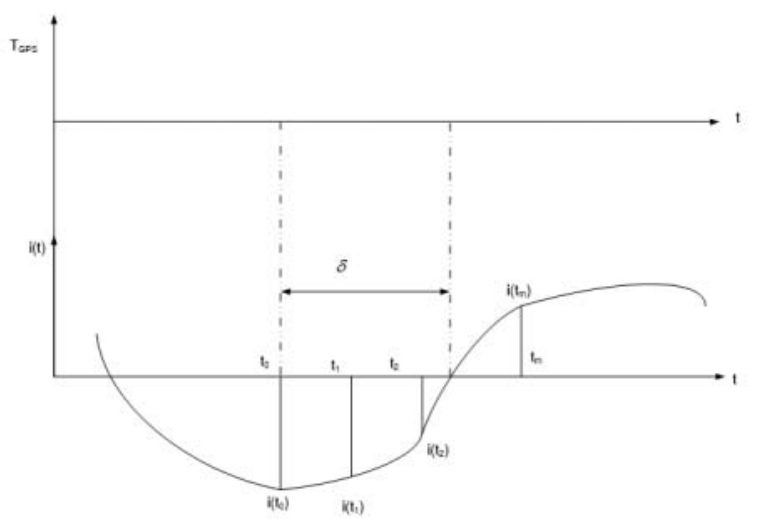

Рис. 1. Синхронне вимірювання сигналів скористуємось прямим диференційним перетворення (2) виду $I(k)=\frac{H^{k}}{k !}\left[\frac{d^{k} i(t)}{d t^{k}}\right] t_{0} \quad$ в точці $\mathrm{t}_{0}$, тобто в момент появи сигналу GPS точного часу і вважаючи, що $\mathrm{t}_{\mathrm{m}}-\mathrm{t}_{0}=\mathrm{H}$, напишемо систему лінійних алгебраїчних рівнянь виду

$$
\begin{aligned}
& \frac{t_{1}}{H} I(1)+\left(\frac{t_{1}}{H}\right)^{2} I(2)+ \\
&+. .+\left(\frac{t_{1}}{H}\right)^{n} I(n)=i\left(t_{1}\right)-I(0), \\
&+\frac{t_{2}}{H} I(1)+\left(\frac{t_{2}}{H}\right)^{2} I(2)+ \\
&+. .+\left(\frac{t_{2}}{H}\right)^{n} I(n)=i\left(t_{2}\right)-I(0), \\
& \quad \frac{t_{n-1}}{H} I(1)+\left(\frac{t_{n-1}}{H}\right)^{2} I(2)+ \\
&+. .+\left(\frac{t_{n-1}}{H}\right)^{n} I(n)=i\left(t_{n-1}\right)-I(0) \\
& I(1)+I(2)+. .+I(n)=i\left(t_{n}\right)-I(0)
\end{aligned}
$$

(C) Гончарова Л. Л., 2017 
в якій невідомими є Т-дискрети $I(0), I(1), .$. $I(k)$. Розв'язавши систему рівняння (3), одним iз відомих способів, отримаємо набір $\mathrm{T}$ - дискрет $I(0), I(1), . . I(k)$. На основі обчислених аналітичним шляхом сукупність дискрет $I(0)$, $I(1), . . I(k)$ і скориставшись зворотним диференційним перетворенням $i(t)=\sum_{k=0}^{k=\infty}\left(\frac{t}{H}\right)^{k} I(k)$ напишем математичний вираз визначення $\tau_{\delta}$ проміжку часу

$$
i(t)=\sum_{k=0}^{k=\infty}\left(\frac{\tau_{\delta}}{H}\right)^{k} I(k)=0
$$

Відповідно кут $\delta$ вичислюється наступним чином. $\delta=\frac{2 \pi \tau_{\delta}}{T}$. Завдяки $\delta$ можна достатньо просто визначати стійкість $\mathrm{S}$ енергосистеми по виразу $S=\frac{d p}{d \delta}>0$, де $\mathrm{P}-$ неактивна потужність, що передається споживачам; $\delta$ - кут фази в точці виміру.

Отримані дані обробляються і проводиться аналіз критичного значення куту $\delta$ відповідної фази i величини стійкості $\mathrm{S}$ електросистеми. Якщо значення параметрів $\delta, \mathrm{S}$ не критичні, то процес синхронного виміру повторюється 3 заданою періодичністю. У випадку коли величина любого параметру приближається до критичного значення, то формується відповідне повідомлення в диспетчерський центр і реалізуються управлінські дії [5].

Інтелектуальні засоби автоматизації. Поняття інтелектуальні пристрої управління пов'язано 3 новим класом математичних моделей, методів і алгоритмів, що відкривають можливість розв'язувати більш досконалі задачі які не спроможні рішати за допомогою традиційних математичних моделей оптимізації. Пристрої, що виконують крім штатних функцій перетворення параметрів реалізують ряд додаткових функцій таких як самодіагностика, технічний контроль стану вузлів виконавчих механізмів, захисту і блокування, стійкості до несанкціонованих впливів, та інші прийнято називати інтелектуальними [4]. Серед сучасних алгоритмів, які використовуються в інтелектуальних пристроях i системах можна виділити алгоритми нечіткої логіки, адаптивного керування, генетичні алгоритми, що імітують процеси відбору в живій природі. В той же час, при реєстрації первинної інформації представленої в аналоговій і дискретній формі, яка відображає режими функціону- вання енергетичних об'єктів і систем, дуже важливим $є$ створення нових інтелектуальних методів i алгоритмів направлених на визначення іï повної інформативності. В цьому плані, представляє суттєвий інтерес використання теорії диференційних перетворень для створення диференційних математичних моделей i методів підвищеної інтелектуальної складності і розмірності як основи інтелектуалізації процесів моніторингу електричного обладнання[2,3,7].

Розглянемо це питання більш докладно, на прикладі інтелектуалізації, сукупності процедур в процесі функціонування силових енергетичних пристроїв. В процесі постачання електроенергії на тягу дуже важливими є пристрої, що виконують комутаційні процедури в яких, в першу чергу, необхідно безперервно контролювати дані про струм, напругу, час горіння електричної дуги, 3 метою надійності функціонування всіх вузлів та механізмів. Головним при цьому $\epsilon$ визначення електричного зношення контактів, що викликається комутацією високовольтної напруги від моменту $\mathrm{t}_{0}$ розмикання контактів вимикача до повного зникнення струму в момент $\mathrm{t}_{\mathrm{m}}$ як показано на рис. 2.

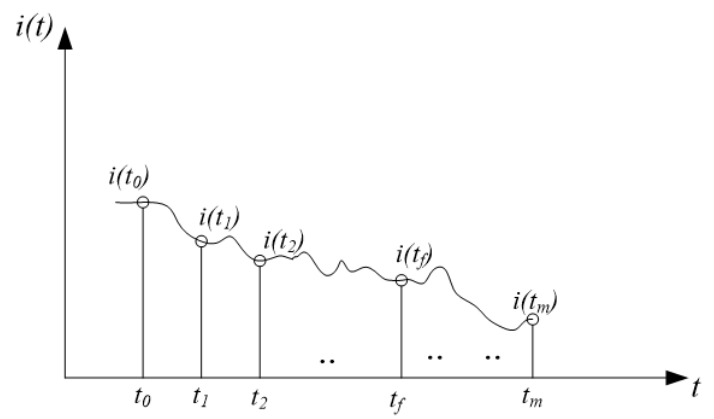

Рис. 2. Процес розмикання контактів високовольтного вимикача струму

Величина $G(t)$, що характеризує електричне зношення контактів, в результаті виконання відповідної комутації, може бути визначена як [5]

$$
G(t)=\int_{t_{s}}^{t_{a}} i^{2}(t) d t
$$

Згідно виразу (2), сукупність миттєвих значень струмів $i\left(t_{0}\right), i\left(t_{1}\right), \ldots i\left(t_{m}\right)$ може бути представлена в сфері диференційних зображень як $I_{f}(k)=i\left(t_{f}\right), \quad f=, 1,2, . . m$, а $i^{2}(t)$, відповідно

$$
i^{2}(t) \mp J(k)=\sum_{l=0}^{l=k} I(l) I(k-l) .
$$

(C) Гончарова Л. Л., 2017 
В матемтичній залежності (6), при $k=0,1,2, .$. отримаєм сукупність дискрет

$$
\begin{array}{cc}
k=0 & J(0)=I(0) I(0)=I^{2}(0), \\
k=1 & J(1)=I(0) I(1)+I(1) I(0)= \\
& =2 I(0) I(1), \\
k=2 & J(2)=I(0) I(2)+I(1) I(1)+ \\
& +I(2) I(0)=2 I(0) I(2)+I^{2}(1) .
\end{array}
$$

На основі виразу (7), інтеграл представлений формулою (5) може бути записаний насупним чином [7]

$$
\begin{gathered}
G(t)=\int_{t_{0}}^{t_{m}} i^{2}(t) d t= \\
=\sum_{k=0}^{k=\infty} \frac{t_{n}^{k+1}-t_{0}^{k+1}}{(k+1) H^{k}} \sum_{l=0}^{l=k} I(l) I(k-l)
\end{gathered}
$$

При $t_{0}=0$ i $t_{m}=\mathrm{H}$ інтеграл $G(t)$ визначається наступним чином

$$
G(t)=\sum_{k=0}^{k=\infty} \frac{1}{(k+1)} \sum_{l=0}^{l=k} I(l) I(k-l)
$$

Враховуючи, що $G(t)=G(k)$, то можна записать

$$
\begin{array}{ll}
k=0, & G(0)=J(0)\left(t_{m}-t_{0}\right), \\
k=1 & G(1)=J(1)\left(\frac{t_{m}^{2}-t_{0}^{2}}{2 H}\right), \\
k=2 & G(2)=J(2)\left(\frac{t_{m}^{3}-t_{0}^{3}}{3 H^{2}}\right)
\end{array}
$$

.На основі виразу (10), організація обчисльвального процесу значення інтегралу $G(t)$ згідно матемтаичній залежності (9), може бути

\section{СПИСОК ВИКОРИСТАНИХ ДЖЕРЕЛ}

1. Стасюк О. І., Гончарова Л. Л., Максимчук В. Ф. Методи організації інтелектуальних електричних мереж залізниць на основі концепції SMARTGrid. Інформаційно-керуючі системи на залізничному транспорті. 2014, № 2. С. 29-37.

2. O. I. Stasuk and L. L. Goncharova, "Differential mathematical models to investigate the computer network architecture of an all-mode system of control over a distance of railways," Cybernetics and Systems Analysis, Vol. 53, No. 1, 157-164 (2017). Cross RefGoogle Scholar.

3. O. I. Stasuk and L. L. Goncharova, "Mathematical models of computer intellectualization of technologies for synchronous phasor measurements of parameters of electric networks," Cybernetics and реализована на основі наступної математичної залежності

$$
G(t)=H \sum_{k=0}^{k=\infty} G(k) .
$$

Таким чином, на основі теорії диференційних перетворень, відкриваються широкі можливості для формування інтелектуальних математичних моделей, методів і організації інтелектуальнихкомп'ютерних систем керування електропостачанням.

\section{Висновок}

1. Аналіз сучасного стану тягових мереж i силових електричних об'єктів залізниць показал, що суттєве збільшення еффективності їх функціонування тісно пов'язано 3 розробкою нових математичних моделей і методів інтелектуалізації домінуючих процедур управління електропостачанням на тягу шляхом проведення ковзкого моніторингу параметрів режимів вразливих сегментів електромережі.

2. На основі теорії диференційних перетворень Пухова, запропоновано ряд диференційних математичних моделей високої інформаціїної складності і розмірності, відкриваючих можливість проводити інтелектуальний моніторинг штатних i аномальнихх режимів функціонування електричних мереж та силового електричного обладнання.

3. Запропоновано методи синхронизації вимірів значень парметрів режимів систем електропостачання в різних сегментах і вузлах виміру при проведенні безперервного моніторингу i, на їх базі, наведено засоби інтелектуалізації процедур керування силовим електричним обладнанням, що неможливо розвязувати традиційними засобами.

\section{REFERENCES}

1. Stasiuk O. I., Honcharova L. L., Maksymchuk V. F. Metody orhanizatsii intelektualnykh elektrychnykh merezh zaliznyts na osnovi kontseptsii SMART- Grid. Informatsiino-keruiuchi systemy na zaliznychnomu transporti. 2014, № 2. S. 29-37.

2. O. I. Stasuk and L. L. Goncharova, "Differential mathematical models to investigate the computer network architecture of an all-mode system of control over a distance of railways," Cybernetics and Systems Analysis, Vol. 53, No. 1, 157-164 (2017). Cross RefGoogle Scholar.

3. O. I. Stasuk and L. L. Goncharova, "Mathematical models of computer intellectualization of technologies for synchronous phasor measurements of parameters of electric networks," Cybernetics and Systems Analysis, 
Systems Analysis, Vol. 52, No. 5, 825-830 (2016). Math Sci Net Cross Ref MATH Google Scholar.

4. Стасюк О. I., Гончарова Л.Л. Математична модель кібербезпеки мереж керування електропостачанням тягових підстанцій. Кібернетика $і$ системний аналіз. 2017. Т.53, № 3. С. 170-179.

5. Стасюк А.И., Гончарова Л.Л. Математические модели и методы анализа компьютерных сетей управления электроснабжением тяговых подстанций железных дорог. Международный научнотехнический журнал

6. «Проблемь управления и информатики». 2017. № 1. C. 34-43.

7. Буткевич О.Ф., Левконюк А.В., Стасюк О.І. Підвищення надійності моніторингу допустимості завантажень контрольованих перетинів енергосистем. Технічна електродинаміка. 2014. № 2. С. 56-67.

8. Пухов Г.Е. Преобразования Тейлора и их применение в электротехнике и электронике. Київ: Наук. думка, 1978. 259 с.
Vol. 52, No. 5, 825-830 (2016). Math Sci Net Cross Ref MATH Google Scholar.

4. Stasiuk O. I., Honcharova L.L. Matematychna model kiberbezpeky merezh keruvannia elektropostachanniam tiahovykh pidstantsii. Kibernetyka i systemnyi analiz. 2017. T.53, № 3. S. 170-179.

5. Stasiuk A.Y., Honcharova L.L. Matematycheskye modely y metodы analyza kompiuternыkh setei upravlenyia эlektrosnabzhenyem tiahovыkh podstantsyi zheleznыkh doroh. Mezhdunarodnыi nauchnotekhnycheskyi zhurnal

6. «Problemы upravlenyia y ynformatyky». 2017. № 1. S. 34-43.

7. Butkevych O.F., Levkoniuk A.V., Stasiuk O.I. Pidvyshchennia nadiinosti monitorynhu dopustymosti zavantazhen kontrolovanykh peretyniv enerhosystem. Tekhnichna elektrodynamika. 2014. № 2. S. 56-67.

8. Pukhov H.E. Preobrazovanyia Teilora y ykh prymenenye $\mathrm{v}$ эlektrotekhnyke y эlektronyke. Kyiv: Nauk. dumka, 1978. 259 s.

Надійшла до друку 17.05.2017.

Внутрішній рецензент Сиченко В. Г.

Зовнішній рецензент Стасюк O. I.

Проведено аналіз сучасного стану тягових мереж і силових електричних об'єктів. Показано, що суттєве збільшення еффективності функціонування електромереж можливо шляхом інтелектуалізації процедур управління. Запропоновано, на основі диференційних перетворень, диференційні математичних моделей проведення інтеллетуального моніторнгу режимів електромереж. На основі диференційних моделей розроблено методи синхронизації вимірів значень парметрів режимів в різних сегментах і вузлах системи електропотсачання і способи інтелектуалізації процесів керування електропотсачанням

ключові слова: диференційні математичні моделі; методи; синхронізація; інтелектуалізація; моніторинг.

\section{УДК 621.311}

\section{Л.Л. ГОНЧАРОВА (ДУИТ)}

Кафедра «Автоматизация и компьютерно-интегрированные технологии транспорта», Государственный университет инфраструктуры и технологий, 03049, Киев - 49, вул. Лукашевича, 19, тел.: 099-288-12-08, эл. почта: ktarael@yandex.ru

\section{ДИФФЕРЕНЦИАЛЬНЫЕ МОДЕЛИ ИНТЕЛЛЕКТУАЛИЗАЦИИ ПРОЦЕССОВ МОНИТОРИНГА ЭЛЕКТРИЧЕСКОГО ОБОРУДОВАНИЯ ТЯГОВЫХ ПОДСТАНЦИЙ}

Проведен анализ современного состояния тяговых сетей и силовых электрических объектов. Показано, что существенное увеличение эффективности функционирования электросетей возможно путем интеллектуализации процедур управления. Предложено, на основе дифференциальных преобразований, дифференциальные математические модели реализации интеллектуального мониторинга режимов электрических сетей. На основе дифференциальных моделей, разработано методы синхронизации измерений параметров режимов в различных сегментах и узлах системы электроснабжения и способы интеллектуализации процессов управления электроснабжения.

ключевые слова: дифференциальные математические модели; методы; синхронизация; интеллектуализация; мониторинг. 


\section{UDC 621.311}

\section{L. GONCHAROVA (SUIT)}

Department of "Automation and computer-integrated transport technology", State University of Infrastructure and Technology, 03049, Kiev-49, Lukashevich st., 19, tel.: 099-288-12-08, e. mail: ktarael@yandex.ru

\section{DIFFERENTIAL MODELS OF INTELLECTUALIZATION OF THE PROCESSES OF MONITORING OF ELECTRICAL EQUIPMENT OF TRACTION SUBSTATIONS}

The analysis of the current state of the traction networks and power electrical objects. It is shown that a substantial increase in the efficiency of electricity possible through the intellectualization management procedures. Proposed, based on differential transformation, a differential mathematical model implementation of intelligent monitoring of modes of electrical networks. On the basis of differential models developed synchronization methods measurement modes in different segments and nodes of power supply system and methods of intellectualization of control processes of power.

Keywords: differential mathematical methods; models; sync; intelligence; monitoring. 